\title{
Obediência infantil: Conceituação, Medidas Comportamentais e Resultados de Pesquisas
}

\author{
Annie Catharine Wielewicki Bueno \\ Bruna Colombo dos Santos \\ Universidade Estadual de Londrina \\ Cynthia Borges de Moura ${ }^{1}$ \\ Universidade Estadual do Oeste do Paraná
}

\begin{abstract}
RESUMO - A obediência infantil a instruções parentais é um tema amplamente abordado na literatura clínica comportamental. No entanto, há poucos estudos que quantifiquem níveis de obediência em crianças de idades específicas, dificultando o trabalho dos clínicos quanto ao estabelecimento de critérios para definir quais frequências de obediência são "normais" em relação a uma população específica. Este artigo discute as definições do termo obediência, algumas medidas que se mostraram úteis à mensuração desse comportamento, e alguns resultados de pesquisa que apresentam as frequências de obediência em crianças clínicas e não clínicas.
\end{abstract}

Palavras-chave: obediência; instruções; contexto familiar; práticas educativas; medidas de obediência.

\section{Child Compliance: Definitions, Behavioral Measurement and Research Results}

\begin{abstract}
Child compliance with parental instructions is an extensively discussed issue on clinical behavioral literature. However, there are few studies that quantify compliance levels in children of specific ages, making it difficult for clinicians to establish criteria in defining normal frequencies of compliance in a specific population. This paper presents some definitions of the term "compliance", some instruments and measurements that are useful in measuring this behavior, and some research results that present compliance frequencies in clinical and non-clinical children.
\end{abstract}

Keywords: compliance; instructions; family context; educative practices; compliance measurements.

A importância da obediência das crianças às instruções parentais é amplamente documentada na literatura clínica infantil (e.g., Forehand, 1977; Houlihan, Sloane, Jones \& Paten, 1992; Patterson, 1982) em função do papel que desempenha no desenvolvimento de comportamentos de autonomia, autocontrole e socialização das crianças (McMahon \& Forehand, 2005). Infelizmente, como afirmam Brumfield e Roberts (1998), ainda não há estudos que quantifiquem "níveis" de obediência para idades específicas. Consequentemente, não é possível estabelecer um julgamento científico sobre se uma determinada frequência de desobediência é normal ou não. Para os terapeutas infantis, isso é especialmente problemático.

Os terapeutas costumam combinar de forma geralmente subjetiva, informações colhidas por meio de entrevistas, questionários e inventários, e observações clínicas para fazer esse julgamento, procedimento esse que apresenta muitas fraquezas metodológicas. A dificuldade surge quando uma criança de 2 anos de idade apresenta, repetidamente, comportamentos de desobediência com episódios de birra em tarefas diárias simples, e os pais se perguntam: "Isso

1 Endereço para correspondência: Universidade Estadual do Oeste do Paraná - Campus de Foz do Iguaçu, Campus Universitário. Av. Tarquinio Joslin do Santos, 1300 - Foz do Iguaçu, PR. CEP 85870-900. E-mail: cynthia-moura@hotmail.com. é normal?" Para crianças de 10 anos de idade, a resposta "não" seria consensual, mas aos 2 anos de idade, diferenças de opinião podem surgir.

Além disso, comportamentos de não obediência podem constituir o início do desenvolvimento de classes mais amplas de comportamento consideradas problemáticas, as quais podem ter sua aquisição na infância, e evoluir para problemas mais sérios na adolescência (Pacheco, Alvarenga, Reppold, Piccinini \& Hutz, 2005), como é o caso dos Transtornos de Conduta e Desafiador Opositivo, conforme indicado no DSM-IV (APA, 1994).

Brumfield e Roberts (1998) ressaltam que o DSM IV requer que o clínico determine se uma criança "com frequência desafia ou se recusa ativamente a obedecer a solicitações ou regras dos adultos" (critério 3 do Transtorno Desafiador Opositivo). Porém, o que a expressão "com frequência" quer dizer? Dito de outra maneira, quais critérios são utilizados para classificar um comportamento como opositor? Qual "frequência" é considerada normal para saber se o comportamento opositor está excessivo? Os autores também afirmam que o DSM IV especifica que o clínico deve identificar se a frequência de não obediência é maior do que a comumente observada em crianças de mesma faixa etária. No entanto, existem poucas pesquisas que buscam estabelecer qual a frequência normal de desobediência infantil para cada faixa etária. 
Assim, a partir de uma análise comportamental, os objetivos deste trabalho são: (1) definir o termo "obediência"; (2) levantar as variáveis contextuais responsáveis pelo seu desenvolvimento e manutenção; (3) indicar as medidas de obediência que têm sido utilizadas em pesquisas sobre o tema; e (4) apresentar resultados de algumas pesquisas realizadas nesta área.

\section{Algumas Definições de Obediência}

Definir o que seja obediência não é tarefa fácil. McMahon e Forehand (2005) afirmam que parece não existir consenso na literatura sobre o uso desse termo e que as pesquisas não explicitam com clareza os critérios utilizados para se considerar uma dada resposta como obediência ou dão definições muito amplas e vagas. Dessa forma, procurou-se levantar na literatura algumas definições para esse comportamento.

Em um estudo realizado por Chapman e Zhan-Waxler (1982), os autores consideraram obediência os seguintes comportamentos: seguimento de instruções parentais, reparação de "malcriações" e tentativas da criança de recobrar a afeição parental. Wahler (1997) definiu a obediência infantil como a resposta mais adequada da criança à instrução parental, e Wahler e Meginnis (1997), definiram obediência apenas como o seguimento das instruções maternas. Caldarella e Merrel (1997) caracterizaram a obediência como uma dimensão das habilidades sociais de crianças e adolescentes e a definiram como o seguir instruções e regras, completar tarefas e guardar apropriadamente brinquedos e objetos.

Mais recentemente, Mc Mahon e Forehand (2005) utilizaram uma definição de obediência fornecida por Schoen (1983), na qual obediência configura-se por seguimento apropriado de uma instrução para apresentar uma resposta específica dentro de um tempo razoável e/ou designado. Para esses autores, tanto a obediência quanto a desobediência, por definição, são processos de interação que envolvem a pessoa que dá o comando ou faz a regra (neste caso, os pais ou professores) e a pessoa para quem a regra ou o comando é direcionado (a criança).

Mc Mahon e Forehand (2005) descrevem duas definições de obediência que têm sido utilizadas em pesquisas sobre o desenvolvimento de crianças normais: "obediência situacional" e "obediência receptiva ou comprometida". A primeira é baseada na expectativa da ocorrência de punição ou reforço, enquanto a segunda ocorre em um contexto de disposição geral para cooperar. Assim, "obediência situacional” parece referir-se aos comportamentos mantidos por punição ou reforço positivo/negativo com uso de reforçadores arbitrários (como o ganho ou a esquiva da perda de presentes ou privilégios); e "obediência receptiva ou comprometida" parece referir-se a comportamentos mantidos pelas consequências sociais intrínsecas ao colaborar mútuo.

Kochanska, Coy e Murray (2001) encontraram, em uma amostra de crianças de 1 a 4 anos, obediência situacional estabilizada na idade de 2 anos, e observaram que obediência comprometida aumentava até a idade de 3 anos. Uma explicação possível para esse achado seria a de que, crianças de 2 anos de idade ainda apresentam um repertório verbal restrito, e dessa forma, respondem mais prontamente às consequências imediatas da situação do que às regras de convivência e colaboração familiar.

Foherand (1977) ainda diferenciou entre a iniciação do obedecer e a finalização de uma tarefa especificada pelo comando de um adulto, dentro de um tempo razoável. Para considerar a iniciação da obediência, autores como Toepfer, Reuter e Maurer (1972), Forehand (1977) e Hupp (2003) determinaram um intervalo de tempo apropriado que permitisse à criança iniciar a tarefa. Esse intervalo tem variado de 5 a 15 segundos, dependendo da idade da criança. Similarmente, Hupp (2003), em pesquisa sobre validação do The Parent Instruction-Giving Game with Youngsters, também considerou obediência quando a criança completava a ação requerida no primeiro mando e no intervalo de 5 segundos. Quando a criança iniciava o seguimento do mando parental, mas não o completava, era considerada obediência parcial.

Outros autores também consideraram respostas de obediência em função do intervalo entre o comportamento requerido e o início da resposta. Toepfer e cols. (1972) classificaram como obediência quando um comando materno era dado e a criança executava a ação imediatamente após o término da descrição da mesma.

Em estudo realizado por Moura (2007), utilizando critérios adaptados de Hembree-Kigin e McNeil (1995), obediência foi definida como o seguimento da instrução, ordem ou pedido, além de respostas às perguntas realizadas pelos pais. Os comportamentos de obediência eram registrados quando realizados imediatamente ou após uma única repetição da instrução pelos pais. Foi considerada tanto a consecução completa do ato requerido, quanto aproximações à resposta final. A latência não foi registrada.

Brumfield e Roberts (1998) afirmam que a obediência infantil é um fenômeno interacional complexo que envolve uma díade específica, por exemplo, mãe-criança ou pai-criança, com história de aprendizagem específica, um contexto social, e instrução com forma e conteúdo. Crittenden e DiLalla (citados por McMahon \& Forehand, 2005) chamam atenção para o fato de que obediência não é a única forma de responder às exigências parentais e é esperado que crianças normais não cumpram integralmente essas exigências. Bolsoni-Silva, Marturano e Manfrinato (2005) afirmam que comportamentos indesejados, como desobediência, são comumente apresentados por crianças sadias em idade pré-escolar e que esta é uma característica transitória do desenvolvimento normal. No entanto, a manutenção ou extinção deste comportamento ocorrerá a partir das consequências por ele produzidas.

McMahon e Forehand (2005) enumeram situações para as quais a desobediência não deve ser caracterizada como comportamento-problema, e sendo assim, não se faz necessário intervir, como quando a desobediência se dá devido a compreensão debilitada da linguagem, como no caso de surdez ou de retardo do desenvolvimento verbal.

Pesquisas realizadas com base em abordagens nãocomportamentais (e.g., Koening, Cicchetti \& Rogoch, 2000; Landauer, Clarsmith \& Lepper, 1970; Stifter, Spinrad \& Braungart-Rieker, 1999), apesar de atribuírem "causas internas" (temperamento, traços de personalidade, internalização de regras etc) ao comportamento de obediência, o definem também em função de instruções, ordens e dire- 
cionamentos parentais. Dessa forma, pode-se observar que, embora existam algumas diferenças entre as definições de obediência, todas elas convergem para um ponto: o de que a obediência só pode ser definida e medida em relação às instruções, ordens, direcionamentos ou pedidos parentais antecedentes.

Uma vez que, no contexto familiar, cada membro afeta o comportamento de outros e é igualmente afetado pelos comportamentos desses membros (Wahler, 1976), as explicações para o comportamento obediente ou desobediente de uma criança devem, provavelmente, ser encontradas no ambiente familiar. Assim, a próxima questão a ser discutida é: quais variáveis contribuem para a aquisição e manutenção do comportamento de obedecer?

\section{Variáveis que Influenciam o Desenvolvimento e Manutenção da Obediência}

Alvarenga (2001), Alvarenga e Piccinini (2007), Huang, Chao, Tu e Yang (2003), Hupp (2003), Salvador e Webber (2005), Salvo, Silvares e Toni (2005), Staats e Staats (1971), Sério (2005), Stifter e cols., (1999) e Wahler (1997), entre outros autores, apontam algumas variáveis que podem aumentar ou diminuir a probabilidade de ocorrência do comportamento de obediência em crianças, dentre elas: desenvolvimento do repertório verbal, antecedentes e consequentes do comportamento de seguir instruções, contexto familiar sincrônico e assincrônico, estressores familiares e práticas parentais de reforçamento.

\section{Desenvolvimento do repertório verbal}

Resultados obtidos por Brumfield e Roberts (1998) em estudo comparativo de duas medidas de obediência, mostraram que os índices alcançados no teste de obediência aumentavam conforme a idade da criança. Crianças de 2 anos a 2 anos e 9 meses de idade obtiveram um índice de obediência de $25 \%$, enquanto crianças de 4 anos a 5 anos e 9 meses de idade apresentaram obediência em $80 \%$ dos mandos.

Em um outro estudo, Stifter e cols. (1999) concluíram que crianças com escores altos em teste de linguagem tinham maior probabilidade em obedecer a ordens parentais para guardar seus brinquedos que crianças com escores mais baixos nesses mesmos testes. Estes resultados levam a hipótese de que o obedecer possa estar diretamente relacionado ao aprimoramento da fala, uma vez que a expansão do vocabulário torna a criança mais apta a compreender e, consequentemente, a seguir instruções que recebe.

O desenvolvimento do comportamento verbal pode ser caracterizado de acordo com o conceito de saltos comportamentais, que segundo Rosales-Ruiz e Baer (1997), refere-se a qualquer mudança de comportamento que leve o organismo que se comporta a entrar em contato com novas contingências e, assim, expandir seu repertório comportamental.

Entendido dessa forma, a aquisição e expansão do repertório verbal é um pré-requisito importante para a apresentação do comportamento de obediência, que como dito anteriormente, depende diretamente tanto das instruções verbais parentais, como pedidos, ordens ou direcionamentos, quanto das consequências reforçadoras para que se mantenha. Assim, tanto antecedentes (pedidos parentais breves, diretos e descritivos), quanto consequentes (valorização da emissão da resposta esperada) podem facilitar a ocorrência do comportamento de obediência.

\section{Antecedentes e consequentes do comportamento de seguir instruções}

Os mandos são operantes verbais nos quais a resposta do falante é reforçada por consequências características providas pelo ouvinte, e estão sob controle funcional de condições relevantes de privação ou estimulação aversiva. Funcionam como uma descrição de contingências, sendo que na maioria das vezes essa descrição é parcial (Skinner, 1957). Por exemplo, um pai, ao chegar do trabalho, liga a televisão para assistir o seu programa favorito e seu filho pequeno começa a brincar com algo muito barulhento. Supõe-se nesse caso, que o barulho funcione como estímulo aversivo para o pai, e este emite uma ordem para o filho: "Pare com esse barulho agora!". Observa-se que, nessa “ordem”, apenas a resposta requerida é descrita, omitindo-se a descrição dos antecedentes e consequentes do comportamento de obedecer. Skinner (1957) aponta que o mando tem como característica beneficiar o falante cessando estimulação aversiva ou condição de privação por meio da mediação do ouvinte. No entanto, para que o ouvinte consequencie adequadamente o comportamento do falante, é necessário que sua resposta tenha sido selecionada pela comunidade verbal por meio de reforçamento diferencial, colocando-a sob controle discriminativo do mando.

Nesse sentido, Baum (1994/2006), assim como Sério (2005), afirmam que a simples presença de uma ordem, instrução, ou conselho, não é condição suficiente para produzir qualquer alteração sobre o comportamento. Nós aprendemos a responder às verbalizações que ouvimos de outras pessoas como estímulos discriminativos verbais. Se não tivermos passado por uma história de reforçamento diferencial na presença desses estímulos, eles não exercerão nenhum controle sobre nosso responder. Isso é importante em relação à obediência infantil, pois se os mandos parentais não adquirirem essa função (estímulos discriminativos verbais), o responder apropriado da criança não é garantido.

Huang e cols. (2003) afirmam que, para que as instruções parentais funcionem como estímulos discriminativos verbais mais efetivos, ou seja, que tenham maior probabilidade de evocar o comportamento requerido, elas devem ser claras, curtas e diretas. Verifica-se que, frequentemente, as instruções parentais são ambíguas e indiretas, o que dificulta o seguimento das mesmas por não especificarem claramente a resposta requerida, a situação em que ela deve ser emitida e tampouco as consequências que a execução ou não execução da resposta acarretariam.

Somado a isso, os pais não esperam um tempo razoável para que a criança possa executar a ação e, muitas vezes, outras instruções são fornecidas sem que a criança tenha tido chance de completar a primeira. Hupp (2003) aponta que a probabilidade de ocorrência do comportamento de obediência 
é aumentada se os pais dão no mínimo 5 segundos para que a criança siga a instrução.

Assim, alterando-se os antecedentes de maneira a prover instruções que possam ser compreendidas pelas crianças e provendo consequências positivas para o comportamento de seguir instruções, muito provavelmente, tem-se um aumento na probabilidade de ocorrência de comportamentos de obediência. Por exemplo, quando um pai pede ao filho que guarde seus brinquedos, além de dar à criança tempo necessário a execução da tarefa, o pai deveria também consequenciar este comportamento com elogios, abraços e beijos. Nessa mesma situação, se a criança não guarda os seus brinquedos, o pai pode consequenciar esse comportamento com castigos, broncas ou retirada de privilégios. Supondo que, no primeiro caso, os elogios, abraços e beijos funcionem como reforçadores secundários positivos, a probabilidade de ocorrência do comportamento será aumentada. E se, no segundo caso, os castigos e broncas funcionarem como estímulos punitivos, a probabilidade de ocorrência do comportamento será diminuída. Logo, percebe-se a importância da consequência na alteração da probabilidade de ocorrência do comportamento.

No entanto, tendo em vista que comportamentos de obediência são importantes para instalar repertórios que serão vantajosos no futuro, como o desenvolvimento de repertórios de autonomia e autocontrole, as consequências providas para esses comportamentos não devem ser apenas reforçadores sociais, como elogios. É importante que os pais descrevam, sempre que possível, as consequências naturais do comportamento executado. Se o comportamento da criança ficar apenas sob o controle dos reforçadores sociais, a probabilidade de emitir comportamentos socialmente desejáveis em situações em que aqueles que disponibilizam esses reforçadores não estão presentes é consideravelmente diminuída.

Seguindo o mesmo exemplo, quando os pais pedem que seu filho guarde os brinquedos que se encontram jogados no meio da sala e a criança assim o faz, além de elogiar o seguimento da instrução, os pais poderiam lhe dizer que quando os brinquedos estão guardados fica mais fácil encontrá-los novamente. Dessa forma, os pais contribuem para que o comportamento da criança fique sob o controle não apenas das consequências que eles provêm, mas também dos efeitos naturais que o comportamento produz no ambiente.

\section{Contexto familiar sincrônico e assincrônico}

Wahler (1997) ressalta a importância do contexto familiar como uma condição ampla que afeta a efetividade dos estímulos discriminativos aos quais a criança responde, bem como a efetividade dos reforçadores disponíveis no ambiente. $\mathrm{O}$ autor destaca dois tipos de contexto familiar: contexto sincrônico e contexto assincrônico.

O primeiro é definido como: "um contexto onde a maioria dos esquemas concomitantes de atenção social parental é seguido por uma classe abrangente de respostas infantis, incluindo respostas de obediência." (p. 194). Dessa maneira, entende-se que, no ambiente sincrônico, as reações parentais ao comportamento infantil são apropriadas, ou seja, acontecem "no tempo certo e da maneira correta". Logo se percebe que uma das características do ambiente sincrônico é a responsividade parental.

A responsividade parental é definida como um fenômeno complexo e multilateral, que deve apresentar no mínimo três elementos diferentes: os pais devem reagir prontamente, consistentemente e apropriadamente às diversas ações e verbalizações das crianças (Harper-Dorton \& Hebert, 1999; Parpal \& Maccoby, 1985; Rocissiano, Salde \& Lynch, 1987; Vigilante \& Wahler, 2005).

Estudos sobre responsividade parental e obediência infantil, apontam que quanto mais responsivos forem os pais, maior a probabilidade de ocorrência de obediência por parte das crianças. Assim, esses estudos demonstram que a obediência infantil é influenciada pelos padrões de respostas parentais somados às respostas específicas destes ao comportamento de obediência. (Parpal \& Macccoby, 1985). Dessa forma, a obediência ocorre como função direta de um contexto sincrônico composto principalmente por reações consistentes dos pais ao comportamento infantil.

O segundo tipo de contexto descrito é o assincrônico. Este contexto é definido como caótico e aversivo, além de ser caracterizado por respostas parentais indiscriminadas a qualquer tipo de comportamento que a criança emita. Wahler (1997) aponta que, nesse contexto, os pais podem estar respondendo a regras que possivelmente foram formuladas na sua história de reforçamento e que não correspondem necessariamente às contingências em vigor. Este fator pode dificultar as interações dos pais com as crianças à medida que seus comportamentos não estão sob o controle do comportamento dos filhos.

Verifica-se que em ambientes assincrônicos há uma maior probabilidade da criança se engajar em qualquer comportamento que produza consequências previsíveis ou consistentes. Isso explica a maior frequência de emissão de comportamentos antissociais por parte de crianças que estão sob condições aversivas típicas do contexto assincrônico, pois esses comportamentos geram consequências previsíveis.

Wahler (1997), ao discutir a influência dos ambientes sincrônicos e assincrônicos sobre a aquisição do obedecer em crianças, classificou os comportamentos emitidos pelos pais em: aprovação, reconhecimento e desaprovação. E os comportamentos infantis em: pró-sociais, neutros e antissociais. Ele observou que, em ambientes sincrônicos, os pais reagem mais frequentemente com aprovação a comportamentos pró-sociais e neutros, e com desaprovação a comportamentos antissociais emitidos pelas crianças. Por outro lado, observou-se que em ambientes assincrônicos os pais reagem com aprovação, reconhecimento e desaprovação com mesma frequência a todas as categorias de comportamento infantil.

Outro ponto importante é que no ambiente sincrônico, a frequência de comportamentos pró-sociais das crianças é significativamente maior do que a frequência de comportamentos neutros e antissociais. Já no ambiente assincrônico, a frequência de comportamentos pró-sociais, antissociais e neutros é similar.

Esses resultados indicam claramente as diferenças de comportamentos parentais e infantis em ambos os tipos de ambientes, e ajudam a identificar possíveis variáveis que podem controlar os comportamentos infantis. Embora Wahler (1997) não tenha especificado quais respostas compõem tais 
categorias de comportamentos parentais e infantis, ele constatou que em ambientes sincrônicos há maior frequência de comportamentos infantis pró-sociais, dentre os quais pode estar incluso o comportamento de obediência. Ele afirma que a obediência infantil é função da sincronia gerada pelas trocas sociais entre a criança e seus pais. "Quando a sincronia é alta, as crianças estão aptas a obedecer às instruções parentais e quando a sincronia é baixa, as crianças são mais prováveis de se tornarem opositoras" (p. 197).

\section{Estressores familiares}

Os estressores familiares podem ser entendidos em termos de operações estabelecedoras, ou seja, como situações que alteram a função de alguns estímulos discriminativos, a probabilidade de respostas a esses estímulos, e também a efetividade de eventos reforçadores (Haydu, 2004).

Wahler (1997) cita alguns estressores familiares que podem influenciar os padrões de interação dos pais com a criança, dentre eles: desvantagem econômica, conflito conjugal e isolamento social. Esses eventos podem funcionar como operações estabelecedoras, uma vez que alteram a função de alguns estímulos discriminativos provenientes do comportamento da criança, e como consequência ocorre alteração das respostas parentais a esses estímulos. Em outras palavras, esses eventos criam condições para que os pais respondam apenas aos estímulos aversivos provenientes dos comportamentos de seus filhos. Assim, um comportamento infantil que poderia ser percebido como neutro pelos pais pode agora adquirir funções aversivas e ter maior probabilidade de ser punido.

Essa alteração no responder discriminativo das mães em relação ao comportamento dos filhos já havia sido descrita em estudos realizados por Wood-Shuman e Cone (1986) e Wahler e Dumas (1984) com mães que enfrentavam problemas com seus filhos. Nesses estudos, as mães assistiam a vídeos de seus próprios filhos e de outras crianças e deveriam responder se as respostas das crianças eram ou não apropriadas. As mães classificaram mais frequentemente o comportamento da criança como "problemático" enquanto observadores treinados viram o mesmo comportamento como neutro.

Esses achados permitem supor que, em função de um contexto estressor, várias classes apropriadas de comportamentos das crianças passam a ser aversivas para os pais e, assim, é provável que eles deixem de consequenciá-los positivamente. E, como foi visto, as consequências positivas são fatores de extrema importância para a aquisição e manutenção dos comportamentos de obediência.

\section{Práticas parentais de reforçamento}

Não é recente o reconhecimento de que é a família o primeiro núcleo de aprendizagem de comportamento para a criança, e de que são os pais os primeiros responsáveis pela modelagem de muitos comportamentos que farão parte do repertório comportamental que será apresentado pela criança em diversas situações. Assim, de acordo com Staats e Staats (1973), os pais assumem, dentre outras, a função de treinadores, já que são eles os primeiros responsáveis pela modelagem dos comportamentos da criança. Skinner (1953/2003) descreve a família como a primeira agência de controle educacional, pois é no contexto familiar que as primeiras práticas de reforçamento são postas em ação.

Salvo e cols., (2005) apontam uma grande quantidade de pesquisas que têm demonstrado a importância da relação pais e filhos e das práticas utilizadas pelos pais na educação dos filhos. As estratégias utilizadas pelos pais na educação de seus filhos - entenda-se educação como modelagem de comportamentos, principalmente os sociais - são denominadas "práticas educativas parentais" e envolvem tanto o número de exigências como as contingências de reforçamento (Alvarenga, 2001; Salvador \& Webber, 2005).

A relação pais e filhos é uma relação dinâmica, ou seja, o comportamento de uma das partes da díade afeta a probabilidade de ocorrência do comportamento da outra. Dessa forma, as práticas educativas parentais são comportamentos dos pais que, durante a interação com seus filhos foram selecionados por produzirem modificações no comportamento destes. Segundo Alvarenga (2001), os pais tendem a utilizar essas estratégias com o objetivo de suprimir ou eliminar certos comportamentos da criança considerados inadequados ou indesejáveis, bem como de incentivar ou favorecer a ocorrência de comportamentos adequados.

Esta autora aponta que as práticas educativas parentais podem ser divididas em duas classes: práticas coercitivas (punição verbal, ameaça de punição, privação ou castigo, coação física e punição física) e práticas não coercitivas (negociação/ troca, explicação apontando consequências, explicação baseada em convenções sociais, mudança nos hábitos da criança com manipulação de condições de privação e saciação, e comando verbal não coercitivo).

Salvo e cols. (2005), baseados na diferenciação de Gomide (2003) sobre as práticas parentais positivas e negativas, destacam a monitoria positiva, ou seja, estar atento aos comportamentos apresentados pela criança e apresentar regras claras com consequências consistentes. Nas práticas negativas são destacados a monitoria negativa ou excesso de monitoria dos pais em relação ao filho, punição inconsistente, negligência, disciplina relaxada, abuso físico, entre outros.

Alvarenga e Piccinini (2007) afirmam que a literatura aponta resultados controversos em relação ao efeito das práticas de reforçamento parental sobre a obediência infantil. Alguns estudos mostram que práticas de reforçamento positivo estão associadas à obediência enquanto outros estudos sugerem que práticas coercitivas também seriam eficazes na produção de obediência. Esses autores apontam que foi encontrada, no estudo de Crockenberg e Littman (1990), forte relação entre obediência e o uso de ordens e pedidos diretos associados à reforçamento positivo contingente à ação da criança. Nesse mesmo estudo, a obediência também esteve relacionada ao uso de sugestões ou orientações associadas a críticas, punições físicas e ameaças.

Outras pesquisas têm demonstrado que diferentes tipos de problemas de comportamento como, por exemplo, agressão, desobediência e delinquência estão relacionados a práticas educativas parentais coercitivas (Bates \& Dodge, 1997; Dodge, Pettit \& Batters, 1994; Rothbaum \& Weisz, conforme citado por Alvarenga 2001). Kochanska (2002), afirma que 
obediência infantil pode ser promovida tanto por práticas de reforçamento positivo quanto por práticas coercitivas. As práticas de reforçamento positivo produzem obediência comprometida, enquanto práticas coercitivas produzem obediência situacional. Os dois tipos de obediência já foram discutidos anteriormente.

A diferença entre as duas práticas reside nos subprodutos que elas geram. O controle aversivo, que inclui reforçamento negativo e punição, gera subprodutos públicos como respostas de fuga e esquiva e também subprodutos privados como comportamentos respondentes e verbais encobertos: raiva, medo, ansiedade etc. Os subprodutos gerados pelo controle aversivo ou coercitivo podem ser entendidos enquanto respostas de contracontrole, que em termos gerais são tentativas do indivíduo de terminar a estimulação aversiva. Assim, se toda vez que uma criança emite um comportamento que os pais identificam como inadequado, e estes pais usam de punição física ou de privação para tentar reduzir a frequência deste comportamento, a criança pode emitir respostas de contracontrole, como fugir da situação, xingar, agredir etc.

Outro problema importante decorrente do uso do controle aversivo, conforme Sidman (1989/2003), é que a punição não propicia a aprendizagem de comportamentos adequados para determinada situação, ensinando, no máximo, o "que não fazer" e na "presença de quem". Um pai que agride o filho todas as vezes que ele está rabiscando a parede do quarto, pode suprimir temporariamente o comportamento (Skinner, 1953/2003), mas não lhe dá oportunidade de aprender outro comportamento que seja funcionalmente semelhante. Assim, seria muito mais proveitoso se, ao invés de dar umas palmadas na criança, o pai lhe explicasse porque não é adequado rabiscar as paredes e lhe oferecesse papel para rabiscar.

Catania (1979/1999) também afirma que estímulos punitivos podem, dependendo do contexto, assumir propriedades discriminativas. Dessa forma, se uma criança está privada de contato com os pais, e em uma determinada situação emite um comportamento que é identificado por eles como inadequado, e este comportamento é consequenciado com uma "surra seguida por afeto de um pai "arrependido", a surra pode assumir controle discriminativo sinalizando que logo em seguida o reforço (afeto) será apresentado.

Por outro lado, as práticas educativas não coercitivas podem favorecer a ocorrência de comportamentos de obediência, já que têm por principais características o uso de regras claras que descrevem contingências reais, além de consequências positivas para o comportamento. As contingências descritas pela regra podem envolver consequências arbitrárias como é o caso da negociação/troca e da explicação baseada na convenção, em que os pais explicitam consequências que serão providas em determinada situação, mas que não são produzidas naturalmente pelo comportamento.

Um exemplo poderia ser quando uma mãe diz ao filho que se ele terminar sua tarefa poderá ir à casa do primo (negociação), ou quando um pai diz ao filho que se ele não obedecer, "Papai do Céu" irá ficar triste (convenção). As regras também podem descrever consequências naturais que serão produzidas pelo próprio comportamento, como quando a mãe explica a criança que deve estudar para passar de ano, para adquirir conhecimentos que lhe serão úteis na vida.

A mudança nos hábitos da criança e o comando verbal não coercitivo também são exemplos de manipulação de condições antecedentes que aumentam a probabilidade de emissão de comportamentos, inclusive de obediência. Como é caso de uma mãe que não fornece guloseimas ao filho antes do almoço, estabelecendo um estado de privação, aumentando dessa forma a probabilidade da criança vir sentar-se à mesa, na hora do almoço, quando é chamada.

Assim, observa-se que as práticas educativas não coercitivas favorecem a aprendizagem dos comportamentos de obediência, e por não envolverem estimulação aversiva não geram subprodutos que podem ser prejudiciais à criança e aos pais.

\section{Medidas de Obediência}

Brumfield e Roberts (1998) afirmam que há dificuldade entre os teóricos quanto ao estabelecimento de "níveis" normais de obediência infantil, em função de que há poucas pesquisas realizadas sobre o tema. Esta dificuldade pode ter implicações clínicas, pois o estabelecimento destas medidas poderia fornecer aos clínicos parâmetros que permitissem: (1) identificar se há necessidade de intervenção; (2) no caso de necessidade de intervenção, avaliar o quão discrepante está a frequência do comportamento de obediência em relação a esse dado normal; (3) avaliar se a intervenção realizada foi eficaz e suficiente para estabelecer medidas normais de obediência infantil.

Considerando o comportamento de obediência infantil, o estabelecimento das medidas quantitativas facilitaria o trabalho de julgamento dos clínicos. No entanto, McMahon e Forehand (2005) apontam a dificuldade em estabelecer quais as taxas normais de obediência e não obediência infantil devido às variações que ocorrem ao longo dos estudos em importantes parâmetros, como a definição, medida, natureza da amostra (normais, em risco, clínicas), idade da criança, natureza do teste e ambiente experimental.

Entre as medidas de obediência mais frequentemente utilizadas em pesquisas estão o Teste Clínico Análogo e o Teste de Obediência. Os dois testes foram utilizados por Brumfield e Roberts (1998) com o objetivo de avaliar e descrever a obediência de pré-escolares normais e selecionar um instrumento de diagnóstico.

\section{Teste Clínico Análogo}

No Teste Clínico Análogo, derivado do Jogo Parental de Forehand e McMahon (1981), o pai (ou a mãe) é conduzido(a) a um ambiente com tarefas programadas para que a criança execute. São distribuídos no chão cinco tipos de brinquedos: fichas de pôquer, pinos plásticos de boliche, blocos de madeira, livros coloridos e canetinhas. O pai é instruído a utilizar suas estratégias de manejo do comportamento infantil. O teste continua até que os brinquedos estejam distanciados da criança ou depois de 10 minutos. 
Esse teste permite que sejam avaliados os modos de instrução e consequenciação parental assim como a probabilidade de obediência infantil.

Os códigos de avaliação parental são instruções alfa e beta e os códigos de avaliação do comportamento infantil são obediência e desobediência. As instruções alfa referem-se a instruções dos pais (ordens, sugestões, questões, regras ou contingências) que especificam uma ação motora da criança. As instruções beta referem-se àquelas que não deixam clara a ação requerida ou que não concedem um tempo adequado para execução da tarefa. Obediência foi definida como iniciativa de resposta motora correspondente à ação requerida pelos pais em até 5 segundos após a instrução. Não obediência é definida como não iniciação da resposta motora especificada.

\section{Teste de Obediência}

O Teste de Obediência, também descrito em um estudo realizado por Brumfield e Roberts (1998), é datado de 1981, quando foi utilizado pela primeira vez. O teste tem apresentado quociente de confiança entre observadores em torno de $97 \%$, alta consistência interna, ambientação moderada, generalização de respostas e boa sensibilidade à intervenção.

No teste original, os pais são treinados a dar 30 instruções padronizadas sobre cada tarefa motora e após cada exigência dar uma pausa de 5 segundos, permitindo que a criança inicie a tarefa. Os comandos devem ser dados de um modo direto e claro e os pais não devem consequenciar os comportamentos da criança, quer sejam de obediência ou de desobediência (Hupp, 2003).

Por essa razão, Hupp (2003) afirma que o Teste de Obediência é utilizado para mensurar a "verdadeira obediência infantil", já que o foco é dado ao comportamento de obediência, supostamente sem influência do comportamento parental. No entanto, como já foi dito anteriormente, os comportamentos de obediência só fazem sentido se vistos em relação aos mandos parentais. E mesmo que o teste não se proponha a avaliar essa relação, ainda assim não é possível prescindir dela.

No estudo de Brumfield e Roberts (1998), algumas alterações foram realizadas no procedimento padrão do Teste de Obediência. O teste envolveu basicamente treinar os pais a dar instruções acerca de uma tarefa motora, seguidas de uma pausa de aproximadamente 5 segundos para que a criança iniciasse a execução da tarefa. $\mathrm{O}$ teste teve duração de 10 minutos e as instruções emitidas pelos pais eram padronizadas e transmitidas a eles pelos experimentadores por meio de "pontos" no ouvido. A sequência de execução da tarefa era constituída de 32 passos que descreviam ações motoras, relacionadas à limpeza, que a criança deveria executar. Os autores apontaram que o Teste de Obediência demonstrou possuir excelente critério para mensurar obediência infantil, mostrando-se mais eficaz do que o Teste Clínico Análogo. O Teste de Obediência também foi usado em um estudo feito por Filcheck, Berry e McNeil (2004), que objetivava determinar os níveis de comportamento disruptivo em crianças, e mostrou resultados satisfatórios.
Uma limitação do Teste de Obediência se refere a não poder ser utilizado como avaliação dos resultados em programas de treinamento para pais, por não avaliar os comportamentos parentais. Outra limitação diz respeito à exclusividade sobre tarefas de limpeza. Em resposta a essa limitação, Powers e Roberts (citados por Hupp, 2003) desenvolveram três simulações nas quais a obediência infantil passou a ser medida durante o levantar-se, vestir-se, hora de refeição, limpar-se e hora de dormir.

\section{O Sistema Codificado de Observação Escolar}

O Sistema Codificado de Observação Escolar (SOCS, do inglês School Observation Coding System; McNeil, Eyberg, Eisenstadt, Newcomb \& Funderburk, conforme citados por Filcheck \& cols., 2004) e a Edição Revisada do Sistema Codificado de Observação Escolar (REDSOCS, do inglês Revised Edition of the School Observation Coding System, Filcheck \& cols., 2004), embora sejam medidas que mensurem outros comportamentos infantis - por exemplo, comportamentos apropriados e inapropriados, comportamentos de inserção ou não inserção na tarefa -, também mensuram comportamentos de obediência e desobediência. Esses testes têm sido usados para discriminar crianças que exibem comportamentos disruptivos e crianças que exibem comportamentos normais (Filcheck \& cols., 2004).

\section{O Questionário de Situações Domésticas}

O Questionário de Situações Domésticas (HSQ, do inglês Home Situation Questionnaire), desenvolvido por Barkley (1987), consiste em uma lista com 16 situações potencialmente geradoras de conflito entre pais e crianças pequenas no contexto doméstico. São elas: (1) brincar sozinho; (2) brincar com outra criança; (3) durante as refeições; (4) vestir-se/ despir-se; (5) escovar dentes/lavar as mãos; (6) tomar banho; (7) quando um dos pais está ao telefone; (8) quando tem visitas em casa; (9) quando a família está fazendo uma visita; (10) em lugares públicos (restaurantes, lojas, igrejas etc.); (11) quando o pai está em casa; (12) quando é pedido que realize pequenas tarefas em casa; (13) quando é pedido para que faça a lição de casa; (14) na hora de dormir; (15) no carro; e (16) quando está com outros cuidadores que não os pais.

Solicita-se ao respondente, pai ou mãe, que assinale “sim” ou "não", considerando se a criança apresenta algum problema em obedecer instruções, ordens ou regras dos pais nas situações descritas. Se "sim", é solicitada uma avaliação da severidade do problema numa escala de 1 (leve) a 9 (severo). A avaliação dos pais resulta nos seguintes escores: número total de situações problemas, escore total da severidade dos problemas e média da severidade do problema. A média de severidade é obtida pela divisão do escore total de problemas pelo número total de problemas.

O QSD também pode ser usado como um instrumento componente para avaliar a efetividade de programas de treino de pais no manejo das situações que envolvem comportamentos de desobediência (Huang \& cols., 2003). 


\section{Sistema de Codificação de Comportamento}

Forehand e McMahon (1981) desenvolveram o Sistema de Codificação de Comportamento (BCS, do inglês Behavioral Coding System) para ser usado durante interações lúdicas entre pais e filhos. Essas interações são dividas em dois momentos: 5 minutos de brincadeira livre da criança sem a participação direta dos pais; e 5 minutos de brincadeira dirigida pelos pais (Hupp, 2003; Hupp, Reitman, Forde, Shriver \& Kelley, 2008). Os comportamentos parentais são categorizados como: comandos, avisos, questões, cuidados, recompensas e timeout. Os comportamentos infantis são categorizados em: comportamentos de obediência e comportamentos desviantes.

O Teste Clínico Análogo administrado em situações domésticas, e o Teste Clínico Análogo padrão, utilizam-se do BCS para codificar os comportamentos de pais e filhos que surgem em tarefas domésticas de limpeza e em tarefas clínicas.

\section{Jogo de Instrução Parental com Crianças Jovens}

O Jogo de Instrução Parental com Crianças Jovens (PIGGY, do inglês Parent Instruction-Giving Game with Youngsters) foi desenvolvido a partir do BCS e seu formato é similar ao do Teste de Obediência. Provê um método padronizado de observação de interações pais-filho e permite observar as habilidades parentais e os comportamentos infantis de maneira a melhorar a identificação precoce e prevenção de problemas infantis (Hupp, 2003; Hupp \& cols., 2008; McMahon \& Forehand, 2005).

Esse jogo é de fácil codificação e pode ser administrado para muitas crianças em ambientes como escola, casa e clínica. Nele, os pais instruem seu filho a obedecer a seus comandos. No total são 20 instruções divididas em cinco momentos. Em cada momento, são dadas quatro instruções de tarefas: duas das tarefas requeridas são de limpeza (e.g., colocar um bloco na caixa e colocar um livro sobre a mesa) e duas tarefas não são relacionadas à limpeza (e.g., sentar na cadeira e bater na porta).

A cada 35 segundos, uma voz gravada diz um número indicando qual a próxima instrução a ser fornecida pelos pais à criança. Os números correspondem a cartões com desenhos representando cada uma das quatro tarefas, como por exemplo, uma figura de uma cadeira. As figuras são utilizadas no lugar de sentenças para que os pais forneçam a instrução de maneira mais próxima à da instrução fornecida habitualmente.

Tem sido desenvolvida uma codificação específica para o PIGGY que inclui códigos de outras medidas, como o BCS. Os códigos do PIGGY são divididos em: comandos parentais, comportamento infantil e consequências parentais. Os comandos parentais são classificados como diretos ou indiretos e durante cada sequência do comando observa-se se os pais disponibilizaram um tempo adequado (pelo menos 5 segundos) para que a criança o cumprisse ou se a criança não teve tempo hábil para obedecer antes que o comando fosse repetido. Os comportamentos infantis são divididos em baixa obediência, desobediência, comportamento verbal inapropriado e comportamento físico inapropriado e obediência imediata (em até 5 segundos após o comando). As consequências parentais aos comportamentos de obediência infantil são categorizadas como elogio típico e elogio atípico. Essas consequências podem incluir estratégias de disciplina tais como timeout e direcionamento físico, e podem também ser categorizadas como super-reativas.

McMahon e Forehand (2005) afirmam que esse jogo pode ser utilizado tanto na avaliação das dificuldades de interação entre pais e filhos quanto no monitoramento dos efeitos do tratamento de crianças.

\section{Questionário de Obediência Probabilística (CPQ)}

O Questionário de Obediência Probabilística (CPQ, do inglês Compliance Probability Questionnaire) é utilizado com menor frequência que outros. Consiste em aproximadamente 120 itens, representando uma longa lista de pedidos dos pais dirigidos aos filhos. Os itens incluem higiene, vestimentas, lazer e atividades sociais, e os pais avaliam a probabilidade de obediência infantil para cada pedido. $\mathrm{O}$ maior benefício do CPQ pode ser identificar os tipos de pedidos que os pais utilizam durante os procedimentos de avaliação observacional (Hupp, 2003).

\section{Resultados de Pesquisas}

Em busca realizada na base de dados PsycINFO, foram encontrados 117 artigos relacionados aos termos compliance e child e 13 artigos relacionados aos termos measure, child e compliance, dois quais, nove apresentavam resultados de medidas de obediência infantil. Tais estudos estão sintetizados no Quadro 1, quanto ao procedimento empregado para medir o comportamento, as categorias utilizadas para análise e os resultados obtidos.

Observa-se que a idade mais frequente das crianças que participaram dos estudos descritos foi de 3 a 6 anos. Para essa faixa etária foi encontrada porcentagem de obediência, incluindo obediência situacional e comprometida, variando entre 26 e $94 \%$. Apesar dessa variação, a média de obediência geral para crianças normais foi em torno de $50 \%$.

Dos nove estudos analisados, sete deles (estudos um, dois, três, quatro, seis e nove) indicaram que a obediência infantil está mais relacionada a práticas parentais positivas e ao uso de instruções diretas que especificam o comportamento a ser emitido. Deve-se destacar que mesmo as práticas parentais positivas não estão isentas de elementos aversivos; o que se aponta é que esses elementos sejam empregados de maneira consistente, mas esporadicamente. Sendo assim, tais práticas não resultam em danos para a criança.

Dois estudos (estudos cinco e sete) mostraram que as práticas parentais negativas, como o uso de punição ou restrição física, também levam a altos índices de obediência infantil. No entanto, alguns autores afirmam que tais métodos devem ser evitados por acarretarem subprodutos indesejáveis como ansiedade, medo, raiva etc., mas não há consenso sobre essa afirmação entre os teóricos. 


\begin{tabular}{|c|c|c|c|c|c|c|c|c|c|}
\hline \multirow{2}{*}{ 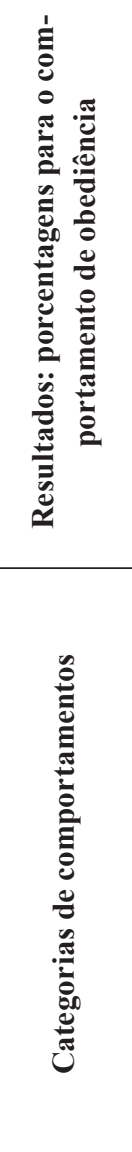 } & \multicolumn{2}{|c|}{ 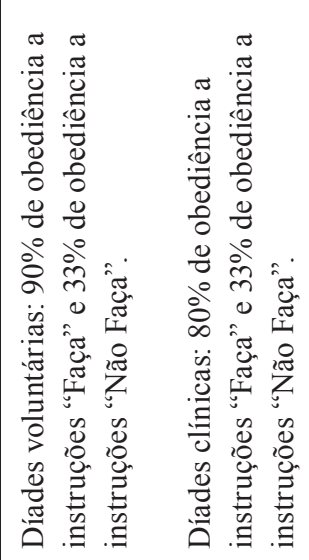 } & 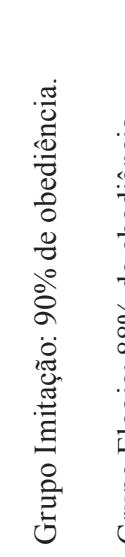 & 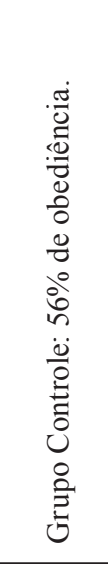 & \multicolumn{2}{|c|}{ 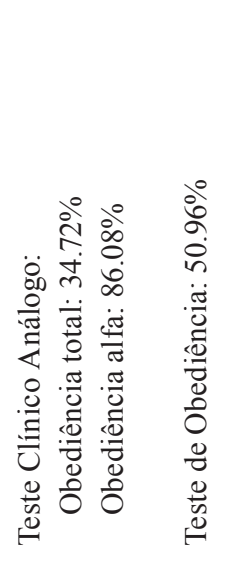 } & \multicolumn{3}{|c|}{ 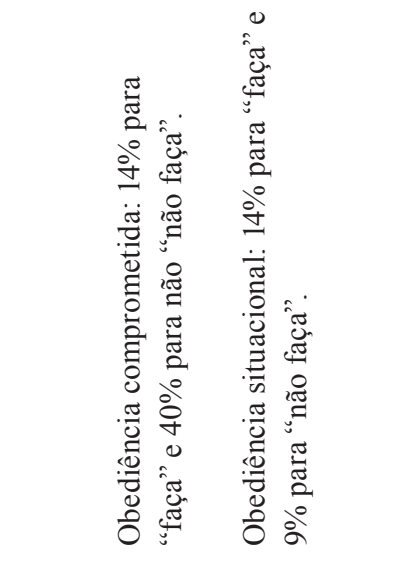 } \\
\hline & 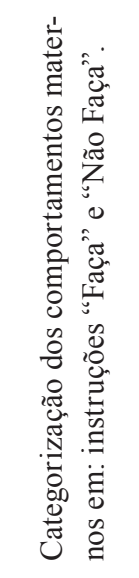 & 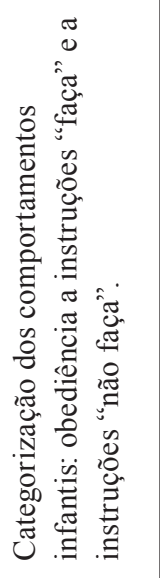 & 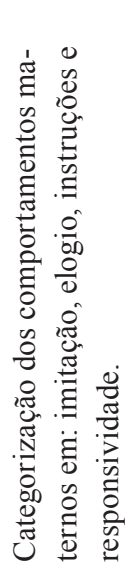 & 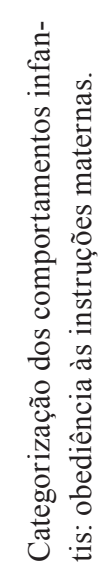 & 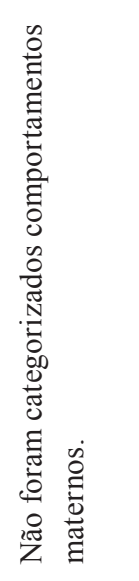 & 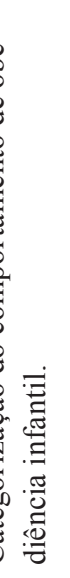 & 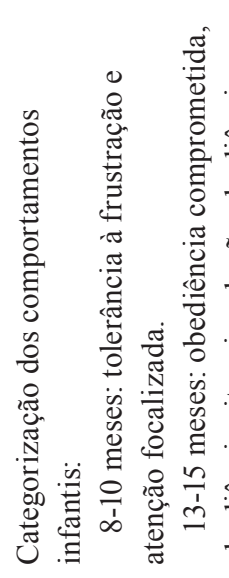 & 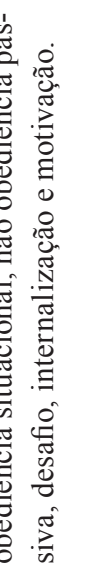 & 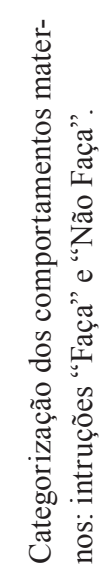 \\
\hline 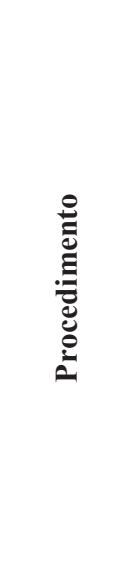 & 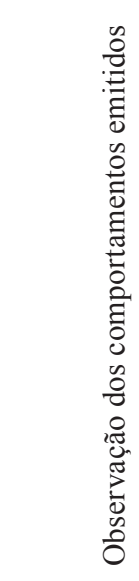 & 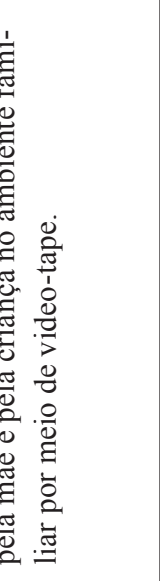 & 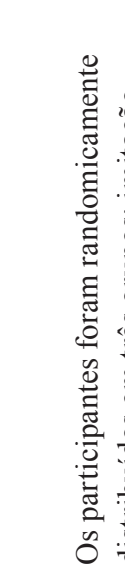 & & 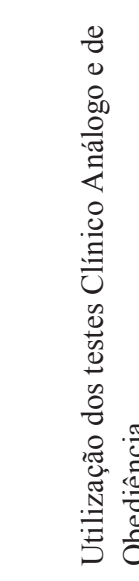 & & 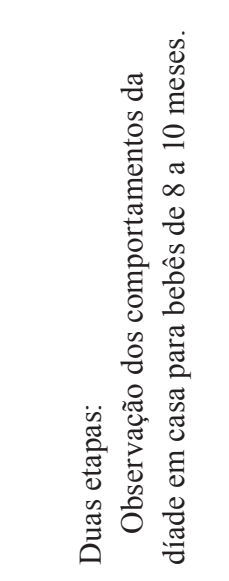 & 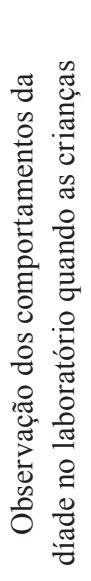 & \\
\hline 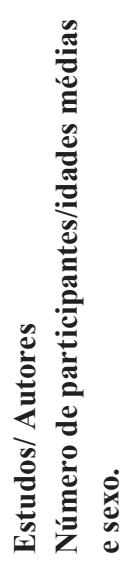 & 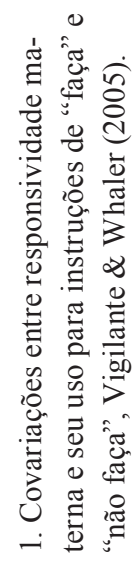 & 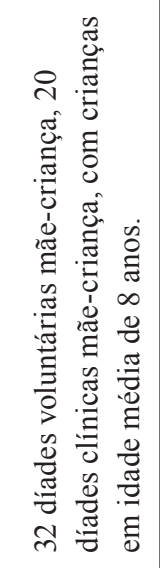 & 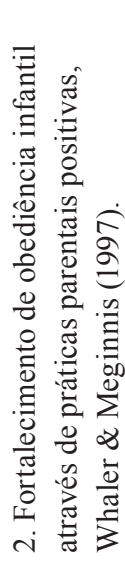 & 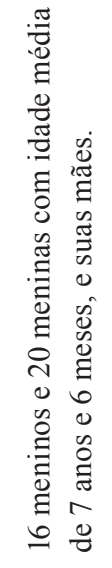 & 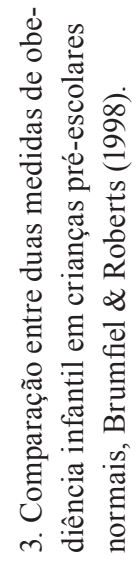 & 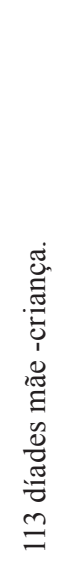 & 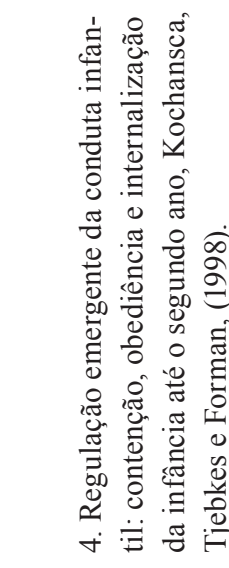 & 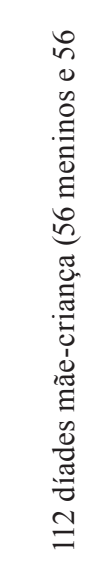 & \\
\hline
\end{tabular}




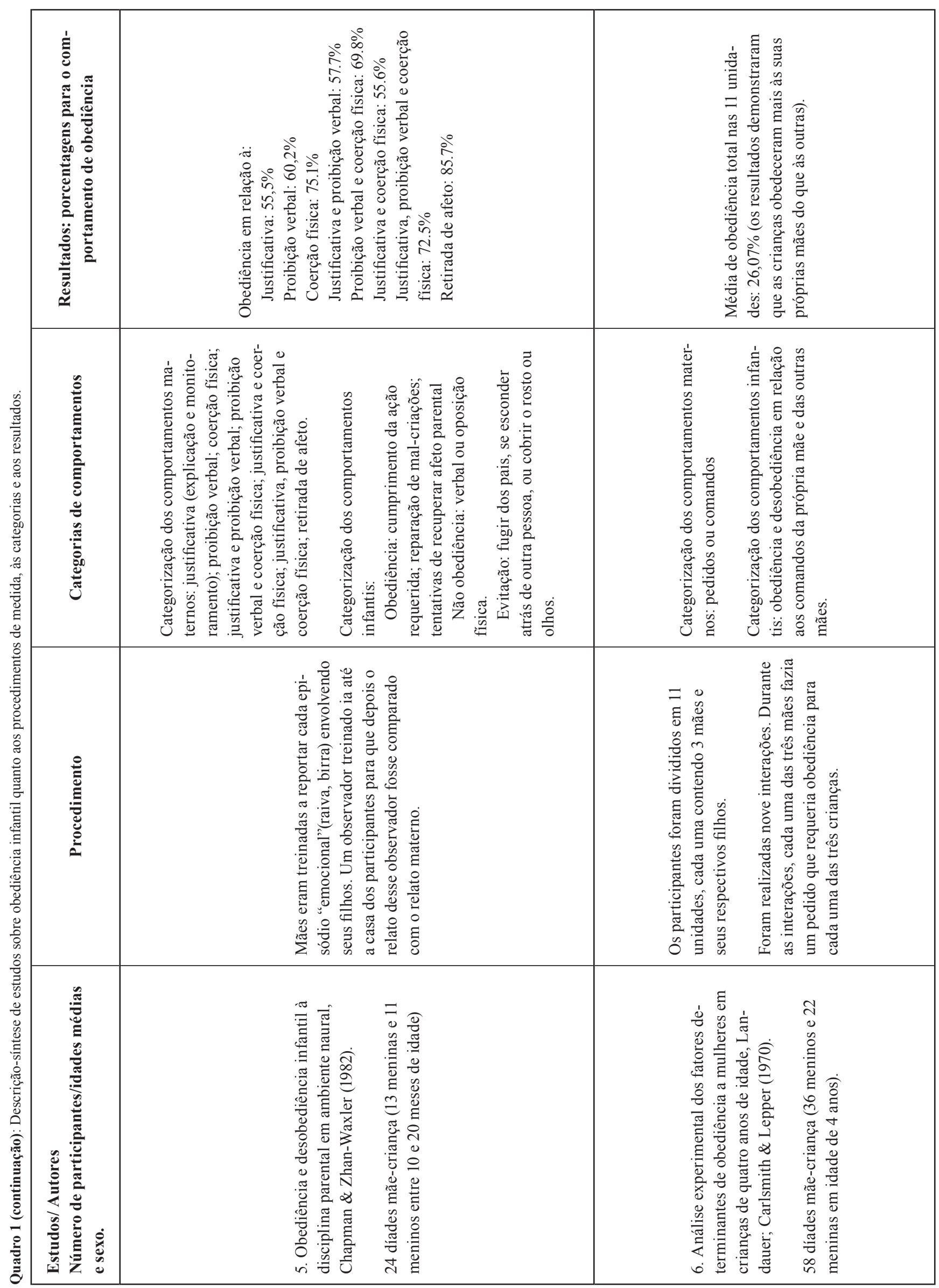




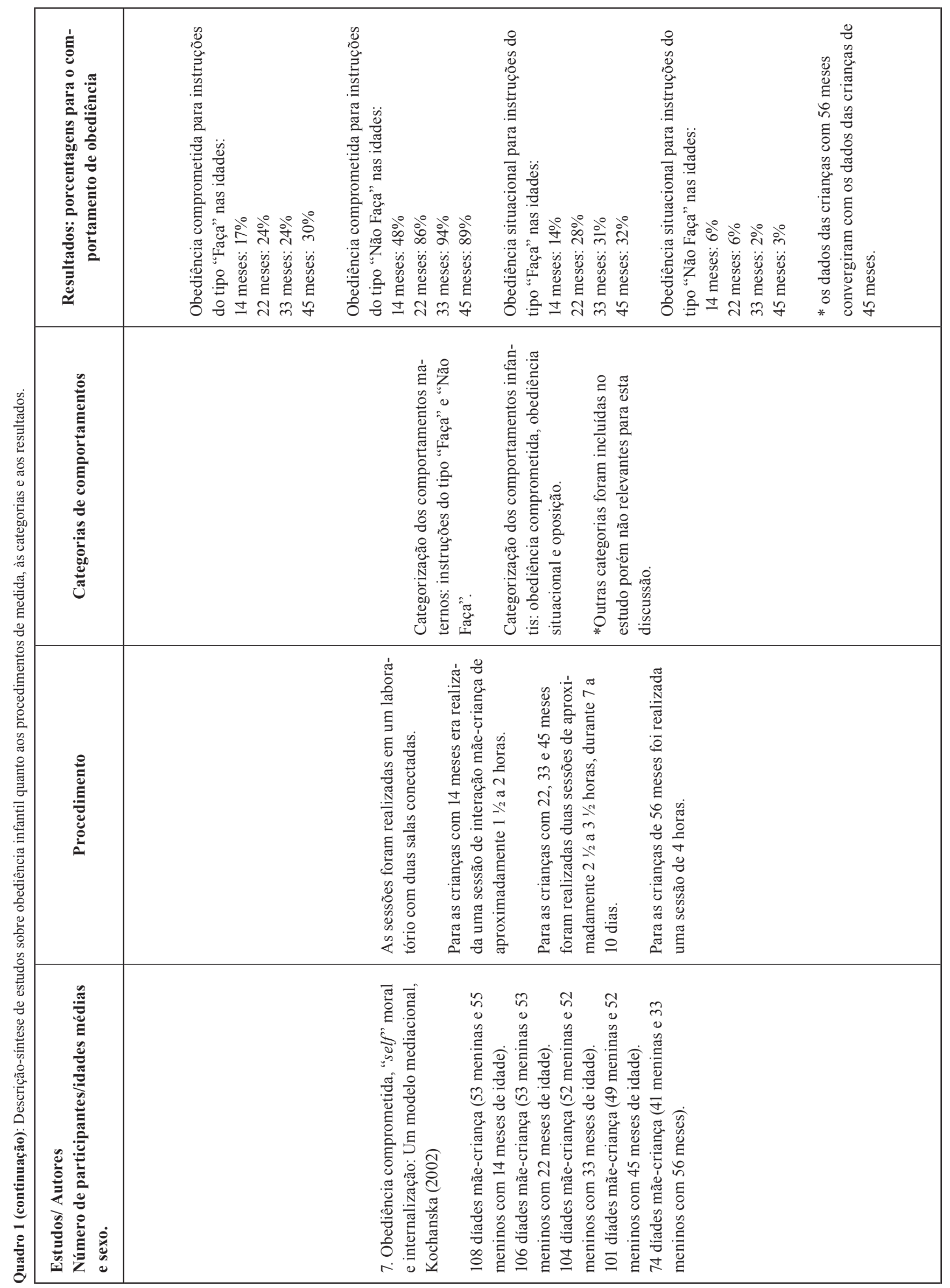




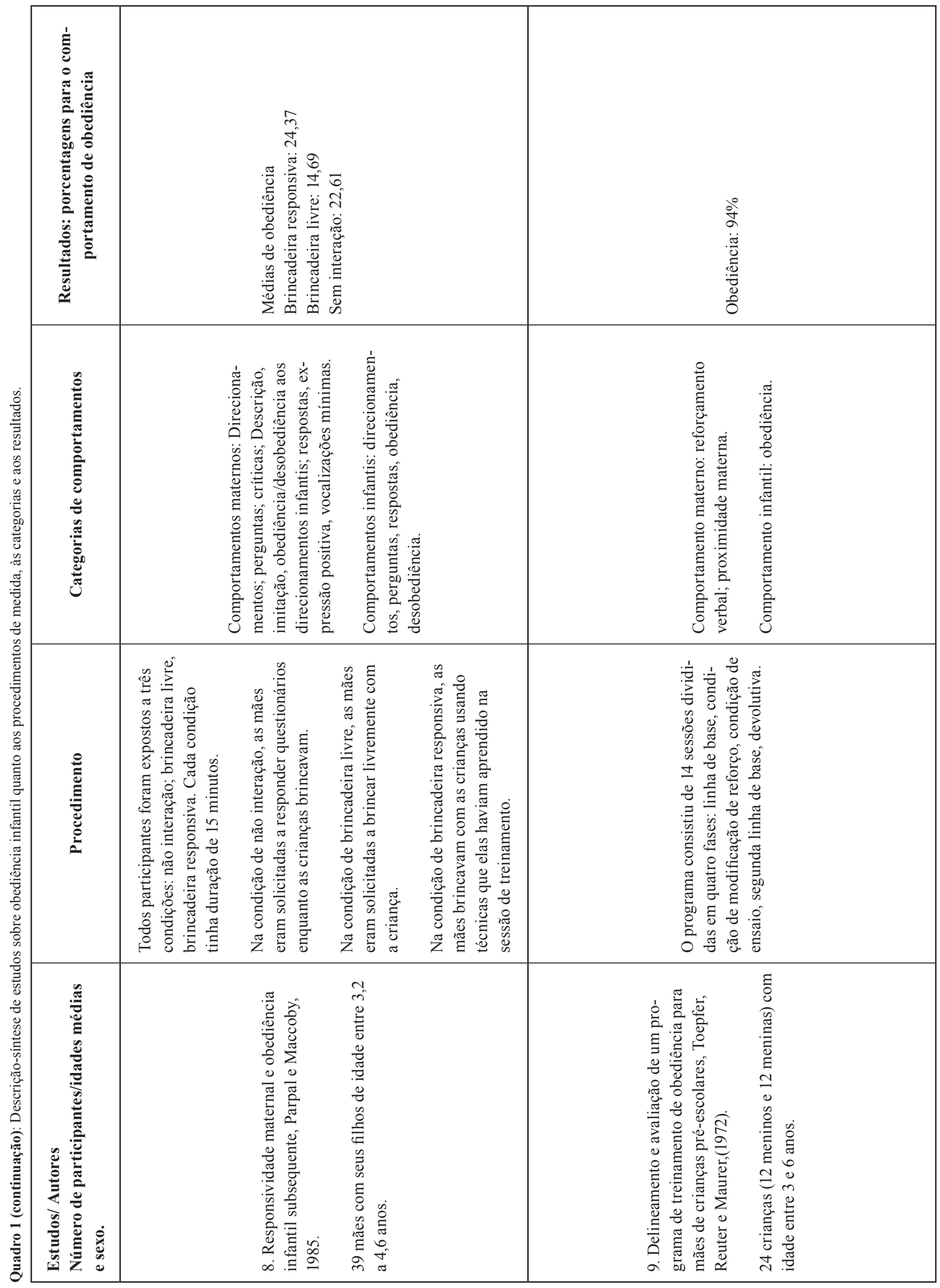


O estudo sete indicou que a obediência infantil aumenta proporcionalmente à idade. Esse dado fornece indícios de que esse comportamento está relacionado à evolução do repertório verbal do indivíduo, o que facilita o seguir regras como já foi dito anteriormente. O estudo seis demonstrou que os filhos obedecem mais prontamente às suas próprias mães que a outras mulheres. Esse dado corrobora a hipótese de que a história de interação mãe-filho influencia na probabilidade de emissão do comportamento de obediência.

Verificou-se, na análise dos estudos, que o comportamento de obediência em crianças pode ser afetado por diversos fatores que já foram amplamente discutidos ao longo deste trabalho. Uma descrição detalhada destes fatores e de como eles afetam o comportamento de obediência pode ter implicações importantes para a pesquisa psicológica e para a prática clínica, como por exemplo, o desenvolvimento de programas que auxiliem os pais no manejo de situações que aumentem a probabilidade de ocorrência do comportamento de obediência.

Apesar deste trabalho ter tentado levantar alguns aspectos importantes no que diz respeito à obediência infantil, ele não esgota as possibilidades de investigação sobre esse tema, dado a notada carência de estudos brasileiros, de estudos que envolvam outros cuidadores que não apenas a mãe, e que apresentem medidas comportamentais que subsidiem os julgamentos clínicos de padrões de normalidade e de problemas de obediência e seguimento de instruções. Por essa razão, algumas das discussões que foram levantadas ao longo deste trabalho, precisam e merecem ser mais bem estudadas, tanto no que diz respeito às definições conceituais, quanto às formulações metodológicas que permitam avançar no conhecimento nessa área.

\section{Referências}

Alvarenga, P. (2001). Práticas educativas parentais como forma de prevenção de problemas de comportamentos. Em H. J. Guilhardi, M. B. B. P. Madi, P. P. Queiroz \& M. C. Scoz (Orgs.), Sobre comportamento e cognição: expondo a variabilidade, Vol. 8 (pp. 52-57). Santo André: ESETec.

Alvarenga, P., \& Piccinini, C. A. (2007). Preditores do desenvolvimento social na infância: potencial e limitações de um modelo conceitual. Interação em Psicologia, 1, 103-112.

American Psychiatric Association - APA (1994). Diagnostic and statistical manual of mental disorders (DSM-IV). Washington, DC: American Psychiatric Publishing Inc.

Barkley, R. A. (1987). Defiant children: Parent-teacher assignments. New York: Guilford.

Baum, W. M. (2006). Compreender o behaviorismo: ciência, comportamento e cultura (M. T. A. Silva, M. M. Matos, G. Y. Tomanari \& E. Z. Tourinho, Trads.). Porto Alegre: Artmed. (Trabalho original publicado em 1994).

Bolsoni-Silva, A. T., Marturano, E. M., \& Manfrinato, J. W. S. (2005). Mães avaliam comportamentos socialmente "desejados" e "indesejados" de pré-escolares. Psicologia em Estudo (Maringá), 10, 245-252.

Brumfield, B. D., \& Roberts, M. W. (1998). A comparison of two measurements of child compliance with normal preschool children. Journal of Clinical Child Psychology, 27, 109-116.
Caldarella, P., \& Merrell, K. W. (1997). Common dimensions of social skills of children and adolescents: A taxonomy of positive behaviors. School Psychology Review, 26, 264-278.

Catania, A. C. (1999). Aprendizagem: comportamento, linguagem e cognição (4a ed.) (D. G. Souza, Trad.). Porto Alegre: Artes Médicas Sul. (Trabalho original publicado em 1979)

Chapman, M., \& Zhan-Waxler, C. (1982). Young children's compliance and noncompliance to parental discipline in a natural setting. International Journal of Behavior Development, 5, 81-94.

Filcheck, H. A., Berry, T. A., \& McNeil, C. B. (2004). Preliminary investigation examining the validity behavioral observation measure for identifying children with disruptive behavior. Child Study Journal, 34, 1-13.

Forehand, R. (1977).Child noncompliance to parental comands: Behavioral analysis and treatment. Em M. Hersen, R. M. Eisler \& P. M. Miller (Eds.), Progress in behavior modification. London: Academic Press.

Forehand, R. L., \& McMahon, R. J. (1981). Helping the noncompliant child. New York: Guilford Press.

Gomide, P. I. C. (2003). Estilos parentais e comportamento anti-social. Em A. Del Prette \& Z. Del Prette (Orgs.), Habilidades sociais, desenvolvimento e aprendizagem: questões conceituais, avaliação e intervenção (pp. 21-60). Campinas: Alínea.

Haydu, V. B. (2004). O que é operação estabelecedora? Em C. E.. Costa, J. C. L. Cecília \& H. H. N. Sant'Anna (Orgs.), Primeiros passos em análise do comportamento e cognição. Santo André: ESETec.

Harper-Dorton, K. V., \& Hebert, M. (1999). Working with children and their families. Chicago: Lyceum Books.

Hembree-Kigin, T. L., \& McNeil, C. B. (1995). Parent-child interaction therapy. New York: Plenum Press.

Houlihan, D., Sloane H. N., Jones, R. N., \& Paten, C. (1992). A review of behavioral conceptualizations and treatments of child noncompliance. Education and Treatment of Children. 15, 56-77.

Huang, H., Chao, C., Tu, C., \& Yang, P. (2003). Behavioral parent training for Taiwanese parents of children with attentiondeficit/hyperactivity. Psychiatry and Clinical Neurosciences, 57, 275-281.

Hupp, S. (2003). The development and validation of the Parent Instruction-Giving Game with Youngsters (Piggy) in a head start population. Tese de Doutorado, Louisiana State University, Louisiana.

Hupp, A. D., Reitman, D., Ford, A., Shriver, D., \& Kelley, L. M. (2008). Advancing the assessment of parent-child interactions: Development of the Parent Instruction-Giving Game with Youngsters. Behavior Therapy, 39, 91-106.

Kochanska, G., Coy, K. C., \& Murray, K. T. (2001). The development of self-regulation in the first four years of life. Child Development, 72, 1091-1111.

Kochanska, G. (2002). Commited compliance, moral self, and internalization: A mediational model. Developmental Psychology, 38, 339-351.

Koening, A. L., Cicchetti, D., \& Rogoch, F. A. (2000). Child compliance/noncompliance and maternal contributors to internalization in maltreating and nonmaltreating dyads. Child development, 71, 1018-1032.

Landauer, T. K., Carlsmith, J. M., \& Lepper, M. (1970). Experimental analysis of the factors determining obedience of four-year-old children to adult females. Child development, 41, 601-611. 
McMahon, R. J., \& Forehand, R. L. (2005). Helping the noncompliance child: Family-based treatment for oppositional behavior. New York: Guilford Press.

Moura, C. B. (2007). Efeitos do vídeo feedback na orientação de mães de pré-escolares com comportamento opositor. Tese de Doutorado, Universidade de São Paulo, São Paulo.

Parpal, M., \& Maccoby, E. E. (1985). Maternal responsiveness and subsequent child compliance. Child Development, 56, 13261334.

Patterson, G. R. (1982). Coercive family process. Eugene, OR: Castalia.

Rocissiano, L., Slade, A., \& Lynch, V. (1987). Dyadic synchronic and toddlers compliance. Developmental Psychology, 16, 54-61.

Salvador, A. P. V., \& Webber, L. N. D (2005). Práticas educativas parentais um estudo comparativo da interação familiar de dois adolescentes distintos. Interação em Psicologia, 9, 341-353.

Salvo, C. G., Silvares, E. F. M., \& Toni, P. M. (2005). Práticas educativas como forma de predição de problemas de comportamento e competência social. Estudos de Psicologia (Campinas), 22, 187-195.

Schoen, S. F. (1983). The status of compliance technology: Implications for programming. Journal of Special Education, 17, 483-496.

Sério, T. M. A. P. (2005). Comportamento verbal. Em T. M. A. P. Sério, M. A. P. A. Andery, P. S. Gióia \& N. Micheletto (Orgs.), Controle de estímulos e comportamento operante: uma nova introdução (pp. 113-138). São Paulo: Educ.

Sidman, M. (2003). Coerção e suas implicações. (M. A. P. A. Andery \& T. M. A. P. Sério, Trads.). Campinas: Livro Pleno. (Trabalho original publicado em 1989)

Skinner, B. F. (1957). Verbal behavior. New York: Appleton Century Crofts.

Skinner, B. F. (2003). Ciência e comportamento humano (11 ${ }^{\mathrm{a}}$ ed.) (J. C. Todorov \& R. Azzi, Trads.). São Paulo: Martins Fontes (Trabalho original publicado em 1953)

Staats, A. W., \& Staats, C. K. (1973). Comportamento humano complexo (C. M. Bori, Trad.). São Paulo: EPU. (Trabalho original publicado em 1963)
Stifter, C. A., Spinrad, T., \& Braungart-Riker, J. M. (1999). Toward developmental model of child compliance: The role of emotion regulation in infancy. Child Development, 70, 21-32.

Toepfer, C., Reuter, J., \& Maurer, C. (1972). Design and evaluation of an obedience training program for mothers of preschool children. Journal of Consulting and Clinical Psychology, 39, 194-198

Vigilante, V. A., \& Wahler, R. G. (2005). Covariations between mother's responsiveness and their use of "Do" and "Don't" instrucions: Implications for child behavior therapy. Behavior Therapy, 36, 207-212.

Wahler, R. G. (1976). Deviant child behavior within the family: Development speculations and behavior change strategies. Em $\mathrm{H}$. Leitenberg (Ed.), Handbook of behavior modification and behavior theory (pp. 516-543). New Jersey: Prentice Hall.

Wahler, R. G., \& Dumas, J. (1984). Changing the observational coding styles of insular and noninsular mothers: A step toward maintenance of parent training effects. Em R. F. Dangel \& R. A. Polster (Eds.), Parent training: Foundations of research and practice (pp. 379-416). New York: Guilford Press.

Wahler, R. G., \& Meginnis K. L. (1997). Strengthening child compliance through positive parenting pratices: What works? Journal of Clinical Child Psychology, 26, 433-440.

Wahler, R. G. (1997). On the origins of children's compliance and opposition: Family context, reinforcement, and rules. Journal of child and Family Studies, 6, 191-208.

Wood-Shuman, S., \& Cone, J. D. (1986). Differences in abusive, at-risk for abuse, and control mothers descriptions of normal child behavior. Child Abuse \& Neglect, 10, 397-405. 